\title{
Diaphragmatic movement in hemiplegic patients measured by ultrasonography
}

\author{
Eytan Cohen, Anne Mier, Peter Heywood, Kevin Murphy, Joe Boultbee, \\ Abraham Guz
}

\begin{abstract}
Background - It is known that automatic breathing is controlled by centres in the lower brain stem, whereas volitional breathing is controlled by the cerebral cortical centres. In hemiplegia, lesions above the brain stem result in paralysis of limb muscles. This study was performed to determine whether the diaphragm might also be affected in patients with hemiplegia.

Methods - Studies were performed in six normal control subjects and in eight patients with complete hemiplegia caused by a lesion above the brain stem, all with no known chest disease. Full lung function tests were performed. Diaphragmatic excursion and inspired volume (VT) were measured simultaneously by $M$ mode ultrasonography and respiratory airflow measurements. Recordings of diaphragmatic excursion were performed on each side separately during volitional and automatic breathing at a similar range of VT.
\end{abstract}

Results - Lung function tests lay within the normal range in all the control subjects. In the hemiplegic patients mean (SD) vital capacity was $79(18) \%$ and residual volume was $123(30) \%$ of predicted. Total lung capacity and functional residual capacity were in the normal range. In the control subjects no significant difference in diaphragmatic excursion was found between volitional and automatic breathing for the same range of inspired volume. By contrast, there was a significant decrease in diaphragmatic excursion during volitional breathing compared with automatic breathing on the affected side in four of the eight hemiplegic patients.

Conclusions - In four of eight hemiplegic patients reduced diaphragmatic movement was present on the paralysed side during volitional inspiration when compared with automatic inspiration. The hemidiaphragm may be involved on the affected side in patients with hemiplegia.

(Thorax 1994;49:890-895)

Breathing can be activated volitionally or automatically via corticospinal and bulbospinal pathways respectively. ${ }^{1}$ The medullary centre for automatic breathing has been investigated extensively ${ }^{2}$ but, until the last decade, little was known about the cortical centres for volitional breathing. Early work revealed an area in the primary motor cortex that resulted in contraction of the diaphragm (hiccough) when stimulated electrically in conscious humans during neurosurgery. ${ }^{3}$ Transcranial electrical stimulation has recently demonstrated an oligosynaptic pathway from the cortex to the diaphragm. ${ }^{4}$ Transcranial magnetic stimulation (TMS) centred on an area $3 \mathrm{~cm}$ lateral to the midline and $2-3 \mathrm{~cm}$ anterior to the auricular plane caused a predominant contralateral response of the diaphragm; a small unilateral response was also obtained in some subjects. Positron emission tomography studies have shown an increase in regional blood flow during volitional breathing in the right premotor and supplementary motor areas, and bilaterally in the primary motor cortex ${ }^{6}$ in the same areas as defined by TMS. In hemiplegic patients with capsular lesions TMS at the vertex showed a longer conduction time to the paralysed side; this provides additional evidence that each hemidiaphragm has a unilateral contralateral cortical representation. ${ }^{\text {? }}$

In hemiplegia caused by a lesion above the brain stem there may be impairment of diaphragmatic movement on the paralysed side. Retrospective viewing of chest radiographs in patients with hemiplegia has shown that the hemidiaphragm on the paralysed side was often higher than the hemidiaphragm on the normal side. ${ }^{8-10}$ Fluoroscopic measurements of diaphragmatic excursion have also shown a smaller excursion of the hemidiaphragm on the paralysed side during a deep volitional breath in some patients with hemiplegia. ${ }^{11}$ Since the height and excursion of the two hemidiaphragms also varies in normal subjects, ${ }^{12-14}$ however, it is difficult to interpret these findings. We therefore decided to compare the diaphragmatic excursion on each side separately, during volitional and automatic breathing, at the same range of tidal breathing. We aimed to record the relation between diaphragmatic excursion and VT in patients with hemiplegia to determine whether it was linear as in normal subjects. ${ }^{15}$ We also compared diaphragmatic excursion at a standard inspired lung volume to see whether it was reduced equally or unequally on the affected side during volitional and automatic breathing. Finally, we wondered whether diaphragmatic excursion of the unaffected hemidiaphragm might be greater to compensate for abnormal movement of the affected hemidiaphragm. 
Table 1 Lung function recordings in normal subjects and hemiplegic patients

\begin{tabular}{|c|c|c|c|c|c|c|c|}
\hline & Age & Sex & $\begin{array}{l}F E V_{1} F V C \\
\text { (\% pred) }\end{array}$ & $\begin{array}{l}V C \\
\text { (\% pred) }\end{array}$ & $\begin{array}{l}T L C \\
\text { (\% pred) }\end{array}$ & $\begin{array}{l}R V \\
(\% \text { pred) }\end{array}$ & $\begin{array}{l}F R C \\
\text { (\% pred) }\end{array}$ \\
\hline Subject 1 & 59 & M & 101 & 89 & 84 & 88 & 83 \\
\hline Subject 2 & 65 & M & 86 & 103 & 89 & 94 & 96 \\
\hline Subject 3 & 73 & M & 96 & 95 & 102 & 137 & 112 \\
\hline Subject 4 & 53 & $\mathrm{~F}$ & 95 & 109 & 110 & 115 & 129 \\
\hline Subject 5 & 66 & $\mathrm{~F}$ & 103 & 103 & 103 & 110 & 114 \\
\hline Subject 6 & 73 & $\mathrm{~F}$ & 105 & 82 & 83 & 90 & 94 \\
\hline Mean (SD) & $65(8)$ & & $98(7)$ & $97(10)$ & $95(11)$ & $106(19)$ & $105(17)$ \\
\hline Patient 1 & 59 & $M$ & 105 & $46^{*}$ & $61^{*}$ & 110 & 84 \\
\hline Patient 2 & 48 & $\mathrm{M}$ & 103 & $70^{*}$ & $76^{*}$ & 89 & 68 \\
\hline Patient 3 & 60 & $\mathrm{~F}$ & 83 & 81 & 113 & $176^{*}$ & $131^{*}$ \\
\hline Patient 4 & 51 & $\mathbf{M}$ & 105 & 92 & 95 & 127 & 106 \\
\hline Patient 5 & 75 & $\mathrm{~F}$ & 132 & 73 & 104 & 122 & 102 \\
\hline Patient 6 & 60 & $\mathrm{~F}$ & - & - & - & - & - \\
\hline Patient 7 & 57 & $\mathrm{~F}$ & 105 & 101 & 97 & 92 & 93 \\
\hline Patient 8 & 68 & $\mathrm{~F}$ & 96 & 89 & 107 & $142^{*}$ & $124^{*}$ \\
\hline Mean (SD) & $60(9)$ & & $104(15)$ & $79(18)$ & $93(19)$ & $123(30)$ & $101(22)$ \\
\hline
\end{tabular}

$\mathrm{FEV}_{1}=$ forced expiratory volume in one second $\mathrm{FVC}=$ forced vital capacity $\mathrm{VC}=$ vital capacity; $\mathrm{TLC}=$ total lung capacity; $\mathrm{RV}=$ residual volume; $F R C=$ functional residual capacity.

*Values $> \pm 2 S D$ of predicted mean.

Results could not be obtained in patient 6 .

\section{Methods}

SELECTION OF CONTROLS AND PATIENTS

Six normal control subjects (three men, three women) of mean (SD) age 65 (8) years were studied. They gave no history of neurological or respiratory disease. The patients had all attended the Charing Cross Hospital, London between July 1992 and July 1993 either as inpatients or as outpatients. Table 1 shows that age matching was achieved but sex matching was not possible. Only those patients who fulfilled the following criteria were studied: (1) dense hemiplegia involving both arm and leg with a unilateral lesion above the brain stem demonstrated by computed tomographic scanning; (2) absence of chest disease on medical history, physical examination and chest radiography; and (3) the ability to take a volitional breath to command. Patients in coma or with receptive dysphasia were excluded.

Of 100 patients who were assessed only eight (three men, five women) fulfilled these criteria and were selected for the study. Their mean (SD) age was 60 (9) years. Five had a right hemiplegia and three had a left hemiplegia. Their brain lesion was either an infarct or a haemorrhage. The time from the stroke to the investigation varied from nine days to 14 months. All subjects and patients gave their verbal informed consent to the studies.

\section{LUNG FUNCTION STUDIES}

Measurements of airways and lung volumes were performed in the lung function laboratory. Volume measurements were carried out using the helium dilution technique.

DIAPHRAGMATIC EXCURSION

Ultrasound records of diaphragmatic excursion were obtained using the same equipment and according to the methods as described previously. ${ }^{15}$ In the present study, however, recordings were performed in the coronal plane as opposed to the longitudinal plane used in the previous paper. The transducer was again held in the fixed frame which could be adjusted so that the transducer was positioned in the midaxillary line pointing towards the dome of the diaphragm (fig 1).

\section{VOLUME MEASUREMENTS}

Subjects breathed through a facemask attached to a hot wire respiratory flowmeter (Minato). The integrated volumes were plotted on a chart recorder (Gould Recorder 2400). Diaphragmatic excursion and volume recordings were synchronised by a simultaneous sound signal on the video tape and mark on the chart recorder respectively.

\section{PROTOCOL OF STUDY}

Simultaneous recordings of diaphragmatic excursion and VT were performed in the supine posture under two different sets of conditions:

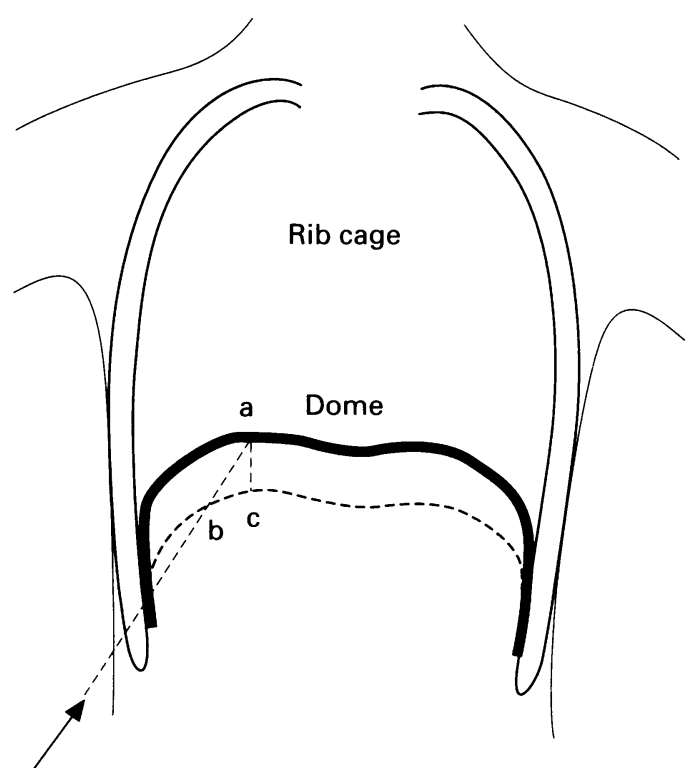

Figure 1 Direction of ultrasound recording in the right coronal plane. Arrow shows position of the ultrasound beam used for $M$ mode tracing; during inspiration the point marked " $a$ " on the diaphragm will move along the line "ac" while the $M$ mode recording will measure distance "ab". 
Table 2 Diaphragmatic excursion at $600 \mathrm{ml}$ during volitional and automatic breathing calculated from the regression equation in six normal subjects

\begin{tabular}{|c|c|c|c|c|c|c|}
\hline \multirow[t]{2}{*}{ Subject no. } & \multicolumn{3}{|c|}{ Right diaphragmatic excursion $(\mathrm{cm})$} & \multicolumn{3}{|c|}{ Left diaphragmatic excursion $(\mathrm{cm})$} \\
\hline & Volitional & Automatic & $p$ & Volitional & Automatic & $p$ \\
\hline $\begin{array}{l}1 \\
2 \\
3 \\
4 \\
5 \\
6\end{array}$ & $\begin{array}{l}1.66 \\
1.22 \\
1.34 \\
1.61 \\
1.48 \\
1.86\end{array}$ & $\begin{array}{l}1.52 \\
1.25 \\
1.24 \\
1.64 \\
1.49 \\
1.77\end{array}$ & $\begin{array}{l}\text { NS } \\
\text { NS } \\
\text { NS } \\
\text { NS } \\
\text { NS } \\
\text { NS }\end{array}$ & $\begin{array}{l}1.47 \\
3.55 \\
2.82 \\
1.73 \\
1.85 \\
*\end{array}$ & $\begin{array}{l}1.39 \\
3.20 \\
2.52 \\
1.88 \\
1.56 \\
*\end{array}$ & $\begin{array}{l}\text { NS } \\
\text { NS } \\
\text { NS } \\
\text { NS } \\
\text { NS }\end{array}$ \\
\hline
\end{tabular}

NS = not significant; $p$ values calculated from confidence intervals (see text).

* Clear recordings not obtained.

(1) automatic breathing when subjects and patients were given no instructions but breathed quietly for several minutes, ideally falling asleep; and (2) volitional breathing at a similar tidal volume range as in (1). To ensure volitional breathing the subjects had a visual feedback of their VT from an oscilloscope positioned in front of them. Two lines could be seen on the screen corresponding to FRC and a VT of one litre respectively. The subjects were instructed and continuously encouraged to take increasing inspired volumes, up to one litre, between those two lines. Three runs of up to 10 breaths were recorded in each subject with a rest pause of at least three minutes between runs. The run where the recordings of diaphragmatic excursion on ultrasound was clearest was later selected for analysis.

\section{Results}

LUNG FUNCTION STUDIES

Lung function recordings lay within the normal range in the control subjects (table 1). Airway measurements were normal in the patients with hemiplegia (table 1). By contrast, vital capacity and total lung capacity were reduced - that is, less than two standard deviations below predicted in two patients (nos 1 and 2), and residual volume was elevated in two (nos 3 and 8 ). Results could not be obtained in patient 6 who, despite repeated efforts, was unable to control her breathing well enough to perform the tests.

\section{DIAPHRAGMATIC EXCURSION AND INSPIRED} VOLUME STUDIES

All subjects and patients tolerated the excursion-volume recordings and had no difficulty in performing the procedure. The left

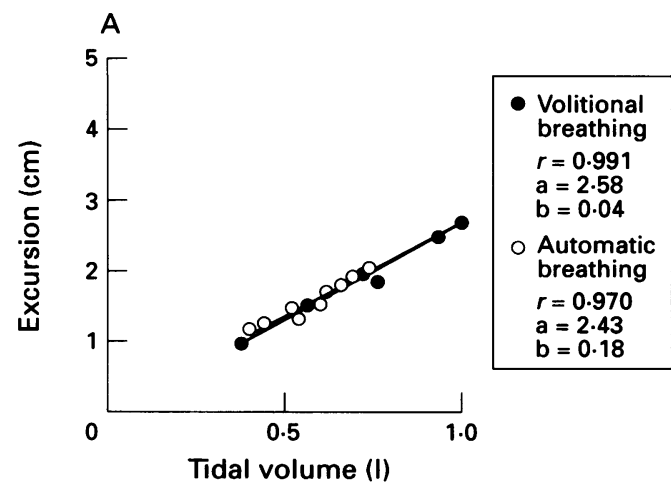

hemidiaphragm could not be visualised adequately in one control subject and in one patient.

During automatic breathing all subjects were completely relaxed and some fell asleep. During the volitional breathing period the evidence that breathing was not automatic was supported by two findings; firstly, the fact that subjects followed the instructions with their eyes open and took increasing inspired volumes and, secondly, the profile of the volume recordings that were not as smooth as during automatic breathing. On average, 10 breaths were analysed for each subject and patient during each mode of breathing.

\section{Normal controls}

Diaphragmatic excursion of the right and left hemidiaphragms in the normal controls during volitional and automatic breathing is shown in table 2. A linear relation between diaphragmatic excursion and VT was found in all the control subjects during volitional $[r=$ $0.99(0.01)]$ and automatic $[r=0.91(0.06)]$ breathing. The excursion-volume curves for the two modes of breathing were very similar (fig 2 and appendix). This linear relation between diaphragmatic excursion and VT enabled us to compare the excursion at a standard VT $(600 \mathrm{ml})$ during volitional and automatic breathing using the appropriate regression equation; predicted confidence intervals (95\% or greater) for diaphragmatic excursion at $600 \mathrm{ml}$ were calculated for each mode of breathing and a significant difference was considered to be present when the predicted intervals did not overlap. The calculated excursion of each hemidiaphragm at $600 \mathrm{ml}$ during volitional and automatic breathing is shown in table 3 . There was no significant difference

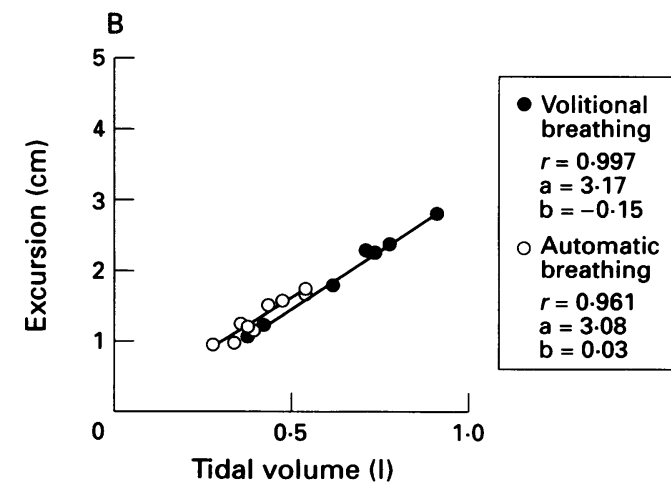

Figure 2 Diaphragmatic excursion-volume relation of $(A)$ the right and $(B)$ left hemidiaphragms during volitional and automatic breathing in a normal subject (subject 4$)$. $a=$ slope (cm/l); $b=$ intercept (cm) with excursion axis. 
Table 3 Diaphragmatic excursions at $600 \mathrm{ml}$ during volitional and automatic breathing calculated from the regression equation in eight hemiplegic patients

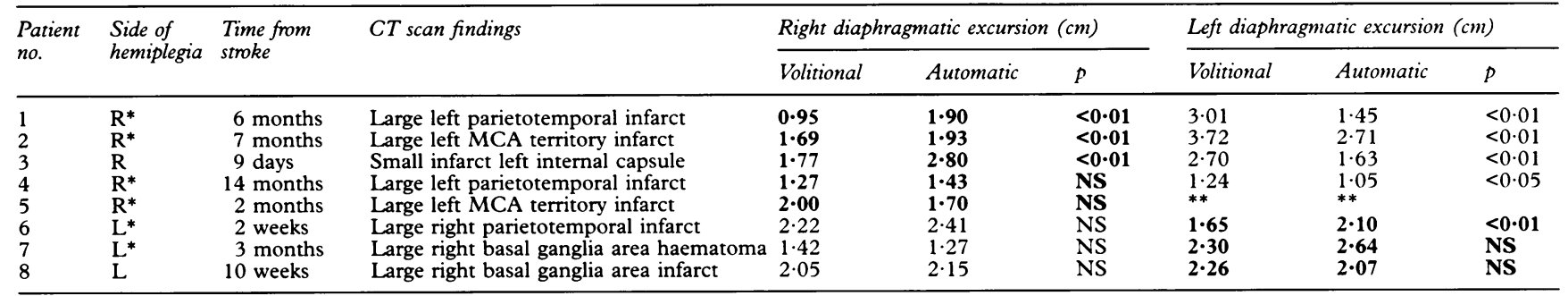

MCA = middle cerebral artery; NS = not significant. $\mathrm{p}$ values calculated from confidence intervals (see text).

* Hemi hypoaesthesia.

** Clear recordings not obtained.

Bold type indicates side of hemiplegia.
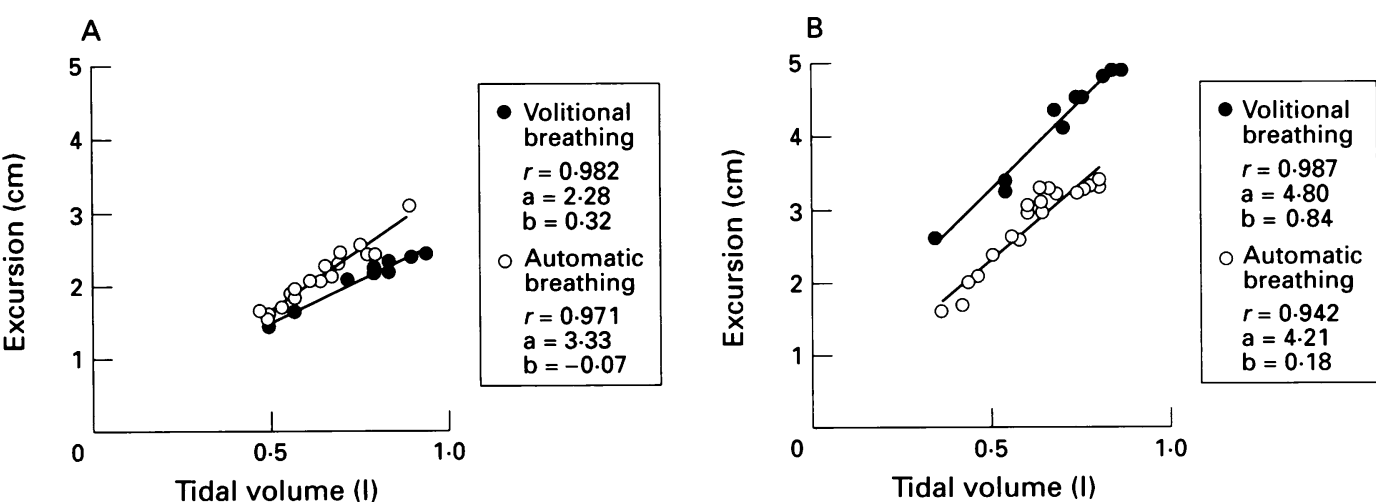

Figure 3 Diaphragmatic excursion-volume relation of $(A)$ the right and $(B)$ the left hemidiaphragms during volitional and automatic breathing in a patient with right hemiplegia (patient 2). $a=$ slope $(\mathrm{cm} / \mathrm{l}) ; b=$ intercept $(\mathrm{cm})$ with excursion axis.

between the two modes of breathing on either side in the control subjects.

\section{Patients with hemiplegia}

A linear relation between diaphragmatic excursion and VT was found in all patients during volitional $[r=0.95(0.03)]$ and automatic $[r=$ $0.92(0.05)]$ breathing. At an inspired volume of $600 \mathrm{ml}$ there was a significant decrease in excursion during volitional compared with automatic breathing on the paralysed side in four of the eight patients (nos 1, 2, 3, 6) (table 3, fig 3). In addition, there was a larger excursion during volitional than during automatic breathing on the non-paralysed side in three of these patients (nos $1,2,3$ ). In patient 4 there was no significant difference in diaphragmatic excursion between volitional and automatic breathing on the paralysed side, but the hemidiaphragm moved more during volitional than during automatic breathing on the unaffected side.

\section{Discussion}

In the last decade increasing knowledge has been gained about the brain centres for volitional breathing. ${ }^{4-7}$ From these data it now seems that the cortical centres for volitional breathing are located bilaterally in the primary motor cortex and that each hemidiaphragm is mainly controlled by a unilateral, contralateral centre. In this paper we have studied the effect of lesions above the brain stem on volitional breathing in a group of patients with hemi- plegia. As we were very strict about the selection criteria we were only able to find eight patients in a period of one year.

Since there was no evidence of airflow obstruction either clinically or on lung function testing, and since the lung parenchyma appeared normal on chest radiography, the high residual volume seen in two of our patients (nos 3 and 8) can be attributed to weakness of the expiratory muscles. The decrease in vital capacity and in total lung capacity seen in two other patients (nos 1 and 2) could be attributed to the weakness of the inspiratory muscles on the hemiplegic side. It is known that lung volumes are not generally affected until respiratory muscle weakness is severe. ${ }^{16}$ In a previous study of 19 hemiplegic patients with no chest disease there was a decrease in their vital capacity to $88 \%$ and $83 \%$ predicted in the male and female patients respectively ${ }^{17}$; in our study the average vital capacity was $79(19) \%$ predicted.

Although previous studies have suggested elevation of the hemidiaphragm on chest radiographs on the affected side in some patients with hemiplegia, ${ }^{8-10}$ we found no such abnormality. There was no significant difference in the position of the hemidiaphragms in our patients, indicating that one cannot rely on chest radiographs alone to detect involvement of the hemidiaphragm in patients with hemiplegia. Using fluoroscopy it has been shown that a decrease in diaphragmatic movement occurs in some patients with hemiplegia on the paralysed side. ${ }^{11}$ However, a major problem in assessing impairment of diaphragmatic movement in patients who have suffered a stroke 
is that a normal variation in excursion exists between the two hemidiaphragms in normal healthy subjects. ${ }^{12-14}$ It has been stated that unequal movement of the two hemidiaphragms is unlikely to be significant unless excursion of the normal side is at least twice as great as that of the affected side. ${ }^{12}$ We therefore decided to compare diaphragmatic excursion at the same range of inspired volume during two different types of respiration, volitional and automatic, on each side separately.

Ultrasonography is a simple and harmless method of viewing the diaphragm and thus is an excellent tool for prolonged recordings of diaphragmatic excursion. The $M$ mode is convenient for measurements, as the beginning and end of each breath can be seen easily. For $M$ mode recordings, scanning in the longitudinal plane is ideal as the transducer can be directed parallel to the cephalo-caudal descent of the diaphragm and exact measurements of diaphragmatic excursion can be made. In a previous paper ${ }^{15}$ we carried out recordings in the longitudinal plane so that we could correlate diaphragmatic excursion with inspired volume. However, the view of the left hemidiaphragm in the longitudinal plane is generally obscured by air in the stomach making recording difficult. In this paper we needed to study both the right and left hemidiaphragms and so we chose to scan the two hemidiaphragms instead, in the coronal plane in the mid-axillary line. In this plane the left hemidiaphragm is scanned through the spleen and can be seen in most cases. Unfortunately it is not possible to aim the $\mathrm{M}$ mode line parallel to the cephalo-caudal descent of the diaphragm in this coronal plane and an angle of around $45^{\circ}$ (fig 1) existed between the direction of descent of the diaphragm and our ultrasound beam. Since the arc cosine of $45^{\circ}$ - the unavoidable angle between the transducer and the diaphragm is 1.4 , we were measuring a diaphragmatic excursion approximately 1.4 larger than the absolute excursion. The transducer was firmly fixed during recordings, however, and we were only interested in the comparison between the automatic and volitional modes of breathing. In addition, the inspired volumes which we recorded were not large, so that any source of inaccuracy would have been constant and small. This different plane of ultrasound recordings between our previous ${ }^{15}$ and present paper would contribute to the difference in diaphragmatic excursion that was reported in the normal subjects in the two papers.

In all subjects a linear relation between diaphragmatic excursion and VT was found. This enabled us to compare the excursion at a chosen tidal volume for both volitional and automatic breathing. Since subjects breathed spontaneously with small inspired volumes during the automatic phase, we felt that it would not be possible to match these small volumes exactly during the volitional phase. We therefore calculated $95 \%$ confidence intervals for diaphragmatic excursion at a chosen inspired volume of $600 \mathrm{ml}$ and determined whether a significant difference between diaphragmatic excursion during volitional and automatic breathing at this inspired volume could be found. In the control subjects there was no significant difference in excursion between the two modes of breathing on either the right or the left side. In four patients, however, there was a significant decrease in excursion on the paralysed side during volitional compared with automatic breathing.

There are several possible explanations as to why abnormal movement of the affected hemidiaphragm during volitional breathing was not found in all our patients with hemiplegia. Firstly, due to the design of the study the patients had to take small inspired volumes during the volitional breathing period to match the volumes of the automatic breathing period. Despite great care being undertaken to ensure that breathing was volitional, we could not be absolutely sure that all breaths were nonautomatic. Secondly, despite obvious lesions on the brain computed tomographic scans on the affected side, the corticospinal projection to the phrenic nucleus may not have been equally affected in all patients. Thirdly, the ipsilateral projection of corticospinal fibres to the diaphragm ${ }^{5}$ may be more significant in some patients than in others.

Our results also give us an insight into the response of the hemidiaphragm on the unaffected side; four patients showed a larger excursion of the hemidiaphragm on the unaffected side during volitional breathing than during automatic breathing. This was not completely unexpected. If the hemidiaphragms had been moving equally before the stroke had occurred, to achieve a specific VT, now that the hemidiaphragm on the paralysed side moved less, the other hemidiaphragm perhaps had to "compensate" by moving more to achieve the same VT. This phenomenon could have resulted from increased neuronal activity occurring from the unaffected side of the brain. Alternatively, the same degree of neuronal activation may have been present but there may have been less impedance to diaphragmatic descent on the unaffected side as a result of reduced descent of the hemidiaphragm on the paralysed side.

In summary, reduced diaphragmatic movement was noted on the weak side in four of eight patients with hemiplegia during volitional breathing compared with diaphragmatic excursion during automatic breathing. We conclude that the hemidiaphragm may be involved on the affected side in patients with hemiplegia.

\section{Appendix}

Regression equations:

(a) Normal subjects:

Right hemidiaphragm volitional breathing: $y=2 \cdot 38 x+0 \cdot 10$ automatic breathing: $y=2 \cdot 28 x+0 \cdot 12$

Left hemidiaphragm volitional breathing: $y=3.91 x-0.05$ automatic breathing: $y=3 \cdot 32 x+0 \cdot 12$

(b) Hemiplegic patients:

Right hemidiaphragm volitional breathing: $y=2 \cdot 71 x+0.02$ 
automatic breathing: $y=2 \cdot 78 x+0 \cdot 28$

Left hemidiaphragm

volitional breathing: $y=3 \cdot 05 x+0 \cdot 59$

automatic breathing: $y=3 \cdot 59 x-0 \cdot 19$

1 Aminoff MJ, Sears TA. Spinal integration of segmental, cortical and breathing inputs to thoracic respiratory motoneurones. F Physiol 1971;215:557-75.

2 Feldman JL. Neurophysiology of breathing in mammals. In: Bloom FE, ed. Handbook of physiology: the nervous system. Vol IV Section 1. USA: American Physiological system. Vol IV Section
Society, 1986:463-524.

3 Foerster O. Handbuch der Neurologie. Vol 6. Berlin: Springer, 1936:1-357.

4 Gandevia SC, Rothwell JC. Activation of the human diaphragm from the motor cortex. F Physiol 1987;384:109-18.

5 Maskill D, Murphy K, Mier A, Owen M, Guz A. Motor cortical representation of the diaphragm in man. $f$ Physiol 1991;443:105-21.

6 Colebatch JC, Adams L, Murphy K, Martin AJ, Lammertsma AA, Tochon-Danguy $\mathrm{HJ}$, et al. Regional cerebral
blood flow during volitional breathing in man. 7 Physiol 1991;443:91-103.

7 Similowski T, Catala M, Orcel B, Willer J-C, Derenne J-P. Unilaterality of the motor cortical representation of the human diaphragm. F Physiol 1991;438:37P.
8 Smith M. The effect of hemiplegia on the diaphragm. $A m$ Rev Respir Dis 1964;89:450-2.

9 Korczyn A, Hermann G, Don R. Diaphragmatic involvement in hemiplegia and hemiparesis. $f$ Neurol Neurosurg Psychiatry 1969;32:588-90.

10 Santamaria J, Ruiz C. Diaphragmatic elevation in stroke. Eur Neurol 1988;28:81-3.

11 Korczyn AD, Leibovitz U, Bruderman I. Involvement of Korczyn AD, Leibovitz U, Bruderman I. Involvement of
the diaphragm in hemiplegia. Neurology 1969;19:97-100. the diaphragm in hemiplegia. Neurology 1969;19:97-100.
Alexander C. Diaphragm movements and the diagnosis of diaphragmatic paralysis. Clin Radiol 1966;17:79-83.
.

13 Young DA, Simon G. Certain movements measured on inspiration-expiration chest radiographs correlated with pulmonary function studies. Clin Radiol 1972;23:37-41.

14 Houston JG, Morris AD, Howie CA, Reid JL, McMillan N. Technical report: Quantitative assessment of diaphragmatic movement - a reproducible method using ultrasound. Clin Radiol 1992;46:405-7.

15 Cohen E, Mier A, Heywood P, Murphy K, Boultbee J, Guz A. Excursion-volume relation of the right hemidiaphragm measured by ultrasonography and respiratory airflow measured by ultrasonography and respi

16 De Troyer A, Pride NB. The respiratory system in neuromuscular disorders. In: Roussos C, Macklem PT, eds. The thorax. Part B. New York: Marcel Dekker, 1985: 1089-121.

17 Haas A, Rusk HA, Pelosof H, Adam JR. Respiratory function in hemiplegic patients. Arch Phys Med Rehabil 1967;48: 174-9. 